\title{
Molecular Architecture of the Circadian Clock in Mammals
}

\author{
Joseph S. Takahashi
}

\begin{abstract}
The circadian clock mechanism in animals involves an autoregulatory transcriptional feedback loop in which CLOCK and BMAL1 activate the transcription of the Period and Cryptochrome genes. The PERIOD and CRYPTOCHROME proteins then feed back and repress their own transcription by interaction with CLOCK and BMAL1. We have studied the biochemistry of the CLOCK:BMAL1 transcriptional activator complex using structural biology as well as the genomic targets of CLOCK and BMAL1 using ChIP-seq methods. We describe the dynamics of the core circadian clock transcriptional system. CLOCK and BMAL1 interact with the regulatory regions of thousands of genes. The gene network and dynamics of the system will be discussed. A mechanistic description of the core circadian clock mechanism should promote our understanding of how the circadian clock system influences behavior, physiology and behavioral disorders.
\end{abstract}

\section{Introduction}

Over the last 20 years, my laboratory has been focused on understanding the molecular mechanism of circadian clocks in mammals. We have used mouse genetics as a tool for discovery of the critical genes involved in the generation of circadian rhythms of mammals (Takahashi et al. 1994; Lowrey and Takahashi 2011). Our initial discovery of the Clock gene using forward genetic screens and positional cloning (Vitaterna et al. 1994; Antoch et al. 1997; King et al. 1997), and the identification of BMAL1 as the heterodimeric partner of CLOCK (Gekakis et al. 1998), led to idea that the CLOCK:BMAL1 transcriptional activator complex

\footnotetext{
J.S. Takahashi $(\bowtie)$

Howard Hughes Medical Institute, University of Texas Southwestern Medical Center, Dallas, TX 75390, USA

Department of Neuroscience, University of Texas Southwestern Medical Center, Dallas, TX 75390, USA

e-mail: joseph.takahashi@utsouthwestern.edu

P. Sassone-Corsi, Y. Christen (eds.), A Time for Metabolism and Hormones,

Research and Perspectives in Endocrine Interactions,

DOI 10.1007/978-3-319-27069-2_2
} 


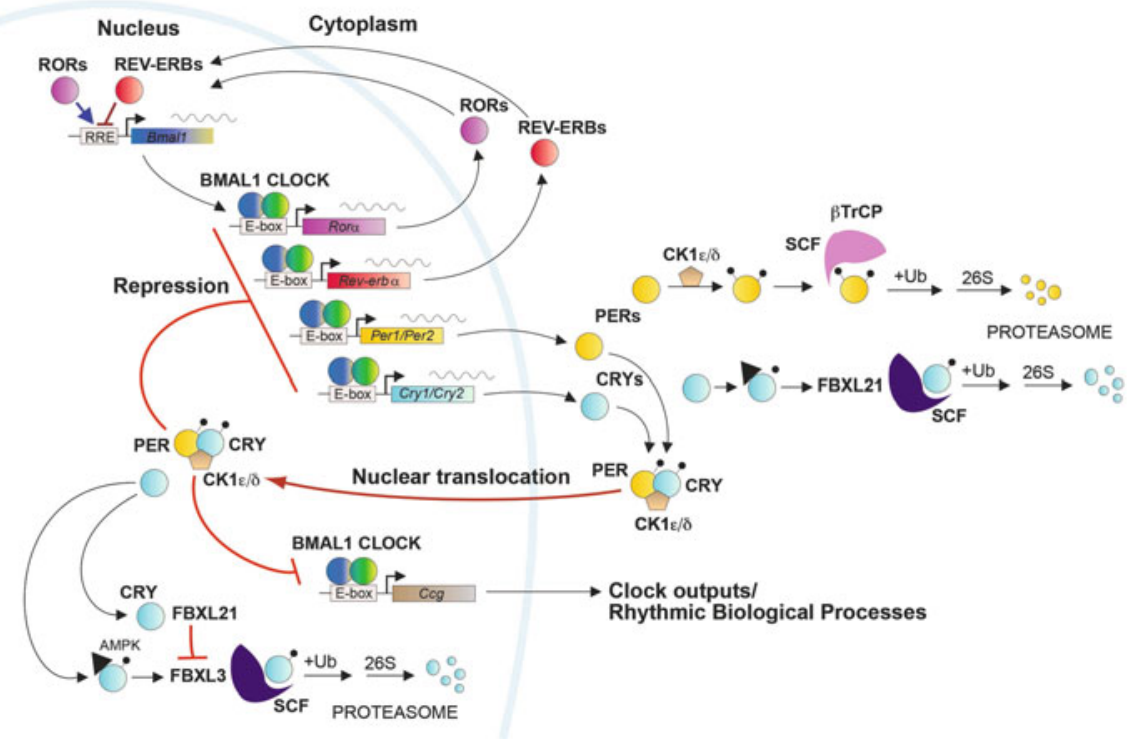

Fig. 1 Model of the circadian clock in mammals. CLOCK and BMAL1 act as master transcription factors to regulate: (1) the Per and Cry genes in the core feedback loop of the clock; (2) the REV-ERB/ROR feedback loop regulating Bmall transcription; and (3) thousands of target genes that are clock outputs. The stability of the PER and CRY proteins is tightly regulated by E3 ubiquitin ligases in both the cytoplasm and nucleus that determine circadian period (Adapted from Mohawk et al. 2012 and Yoo et al. 2013)

was upstream of the Period and Cryptochrome genes, whose gene products then repressed CLOCK:BMAL1 to form an autoregulatory transcriptional feedback loop (Lowrey and Takahashi 2000). Since the identification of these "core circadian clock genes" (i.e., Clock, Bmall, Per1, Per2, Cryl and Cry2), additional feedback loops driven by CLOCK:BMAL1, such as the loop involving Rev-erbo to repress Bmall transcription, have been described (Preitner et al. 2002). In addition, the regulation of the stability of the PER and CRY proteins by specific E3 ubiquitin ligase complexes has been found to be important for determining the periodicity of the circadian oscillation (Busino et al. 2007; Gallego and Virshup 2007; Siepka et al. 2007; Meng et al. 2008; Yoo et al. 2013). Together, this work has led to a description of a model of the circadian clock in mammals (Fig. 1).

With the discovery and cloning of clock genes came the realization that their expression was ubiquitous (Lowrey and Takahashi 2004). We now accept that clock genes are housekeeping genes and are expressed in essentially all cells. What was perhaps even more surprising was the observation made using circadian gene reporter technology that essentially every peripheral organ system and tissue has the capacity to express autonomous circadian rhythms (Yoo et al. 2004). Thus the ubiquitous expression of clock genes is a reflection of the ubiquitous capacity of most tissues and cells to express circadian oscillations. These distributed circadian oscillators are cell autonomous and can function independently of the central clock 
located in the suprachiasmatic nucleus (SCN) (Nagoshi et al. 2004; Welsh et al. 2004; Yoo et al. 2004). The realization that the body is composed of a multitude of cell-autonomous clocks has raised a number of questions concerning the organization of the clock system and the role of the SCN clock in "circadian organization." Elsewhere, we have also explored the role of the SCN as a master pacemaker to synchronize peripheral oscillators (Yoo et al. 2004; Hong et al. 2007; Kornmann et al. 2007; Buhr et al. 2010; Hughes et al. 2012), as well as the role of intercellular coupling in the robustness of the SCN oscillator (Liu et al. 2007; Buhr et al. 2010; Ko et al. 2010; Welsh et al. 2010).

\section{Structural Biology of Clock Proteins}

Despite our general knowledge of clock components and their interactions, the biochemical mechanisms of circadian clock proteins and how they function within the circadian feedback loop are largely unknown. For example, many coding mutations have been described for mammalian clock proteins but, at a macroscopic level, we have little hope of understanding how they exert their phenotypic effects without a deeper understanding of their molecular mechanism. For these reasons, we have turned to structural biology to understand circadian proteins at an atomic level of resolution. Recently, we have solved the three-dimensional structure of the CLOCK:BMAL1 heterodimeric transcriptional activator complex using X-ray crystallography (Huang et al. 2012). The CLOCK:BMAL1 structure reveals an asymmetric heterodimer in which the bHLH, PAS-A and PAS-B domains of each subunit interact with their complementary domains but do so in an unexpected manner (Fig. 2). The PAS-A domains dimerize via symmetrical interactions involving $\alpha$-helical domains (that are N-terminal to the canonical PAS fold) that pack against the $\beta$-sheet surfaces of the PAS-A domains (Fig. 3a). In contrast, the PAS-B domains dimerize in an asymmetric, head-to-tail fashion so that the $\beta$-sheet surface of BMAL1 interacts with the $\alpha$-helical surface of CLOCK (Fig. 3b). A conserved BMAL1 Trp427 residue on an H-I loop (connecting the $\mathrm{H} \beta$ and $\mathrm{I} \beta$ strands) inserts into a hydrophobic pocket on the $\alpha$-helical surface of CLOCK that resembles the co-factor binding pocket in other PAS proteins. Interestingly, a Trp residue is also conserved on the H-I loops of CLOCK, PER1 and PER2 PAS domains, suggesting that an aromatic residue inserting into the PAS receiver pocket may represent a common motif for PAS domain interactions (Crane 2012).

The structure of CLOCK:BMAL1 represents a starting point for understanding at an atomic level the mechanism driving the mammalian circadian clock. Many of the previously identified mutations on CLOCK and BMAL1 can be mapped onto the structure and, for example, predict regions of interaction of CLOCK with the CRY proteins (Huang et al. 2012). The crystal structures for the PAS-A/PAS-B domains of the mammalian PERIOD proteins (Hennig et al. 2009; Kucera et al. 2012), for the photolyase homology domains of the mammalian CRY1 (Czarna et al. 2013) and CRY2 (Xing et al. 2013) proteins, and for the CRY2/ PER2-CRY binding domain complex (Nangle et al. 2014) beg the question of how 


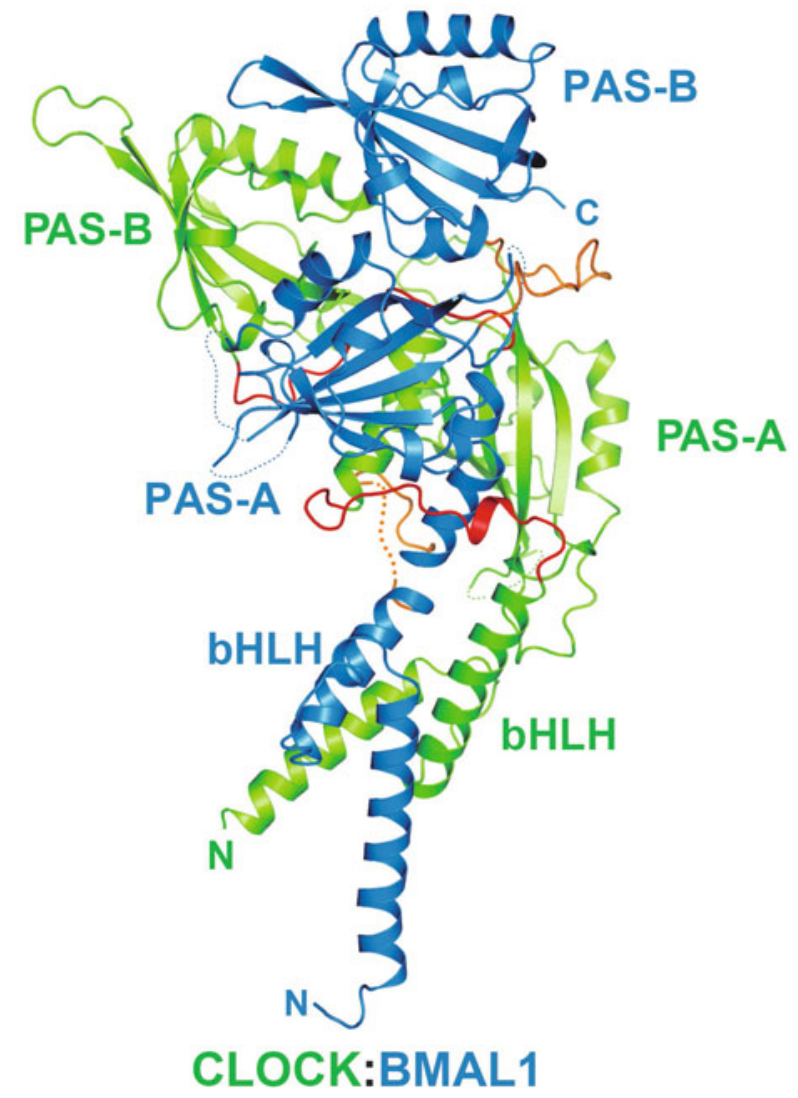

Fig. 2 CLOCK:BMAL1 structure showing bHLH, PAS-A and PAS-B domains. Linker regions shown in red or orange (From Huang et al. 2012)

A

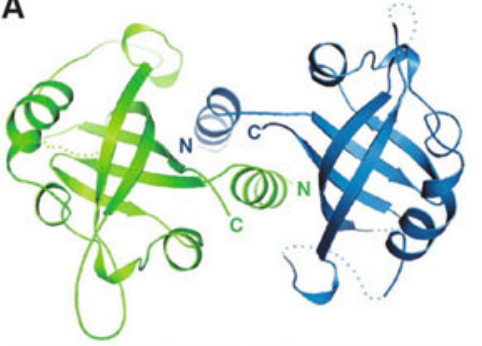

CLOCK PAS-A BMAL1 PAS-A
B

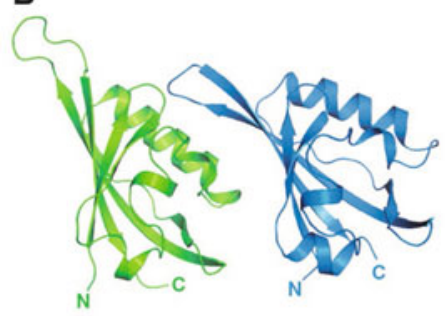

CLOCK PAS-B BMAL1 PAS-B

Fig. 3 PAS domains of CLOCK:BMAL1. (a) PAS-A interactions shown looking down the axis of the complex. (b) PAS-B interactions shown from a side view (From Huang et al. 2012) 
PER and CRY interact with CLOCK:BMAL1 to repress their function. Because the native CLOCK:BMAL1/PER:CRY quaternary complexes are megadalton in size and involve other interacting proteins, and because important domains of these proteins are flexible, the solution of these complexes likely will require a combination of crystallography, NMR, and cryo electron microscopy methods in future work.

\section{Transcriptional Architecture and Chromatin Dynamics of the Clock}

To define the cis-acting targets of the core circadian transcriptional regulators, we used chromatin immunoprecipitation followed by sequencing (ChIP-seq) to locate DNA binding sites for BMAL1, CLOCK, NPAS2, PER1, PER2, CRY1 and CRY2 in vivo in murine liver at six times during the circadian cycle. Figure 4 shows a browser view of the $\mathrm{Dbp}$ locus, a major target gene of CLOCK-BMAL1 (Ripperger and Schibler 2006). The activators BMAL1, CLOCK and NPAS2 bind in a cyclic manner between CT0 and CT12 (CT = circadian time; CT0 is the beginning of the subjective day; CT12 is the beginning of the subjective night) at three locations in the promoter, intron 1 and intron 2. PER1, PER2 and CRY2 bind the same sites with an opposite phase at CT12-20. CRY1 exhibits a third pattern that peaks at CT0.

In genome-wide analysis, CLOCK and BMAL1 bind to over 4600 and 5900 sites, respectively, corresponding to 3000 unique genes (Koike et al. 2012). The repressors CRY1 and CRY2 bind to significantly more sites, and many thousands of these sites are independent of CLOCK:BMAL1 and reveal DNA binding motifs for nuclear receptors (Koike et al. 2012), including the glucocorticoid receptor consistent with recent work (Lamia et al. 2011). To examine functional readouts, we used whole transcriptome RNA-seq to profile cycling genes in the liver using samples taken every $4 \mathrm{~h}$ over $48 \mathrm{~h}$ (Koike et al. 2012). Using the intron RNA signal as a proxy for pre-mRNA, we found 1300 cycling genes and, surprisingly, they were clustered in time with a peak at CT15 (Fig. 5). To explore the possible origins of the global rhythms in nascent transcription, we analyzed the genome-wide occupancy of RNA polymerase II (RNAPII) as a function of the circadian cycle. The large subunit of RNAPII contains a C-terminal domain (CTD) that is modified at various stages of transcription (Sims et al. 2004; Fuda et al. 2009). RNAPII is recruited into the pre-initiation complex with a hypophosphorylated CTD that is recognized by the 8WG16 antibody (Jones et al. 2004). Again to our surprise, we found that RNAPII-8WG16 occupancy was highly circadian across the genome in the liver, with a peak at CT14.5, which preceded the intron RNA peak by $0.5 \mathrm{~h}$ (Fig. 5). Initiation of RNAPII involve phosphorylation on serine 5 (Ser5P) on the CTD of RNAPII and is recognized by the 3E8 antibody (Chapman et al. 2007). We found that RNAPII-Ser5P occupancy was also circadian, with over 13,000 sites that were significant for cycling. The timing of RNAPII-Ser5P peaked at CT0 and coincided with the peak of CRY1. At this time we found an association of CRY1, CLOCK, 


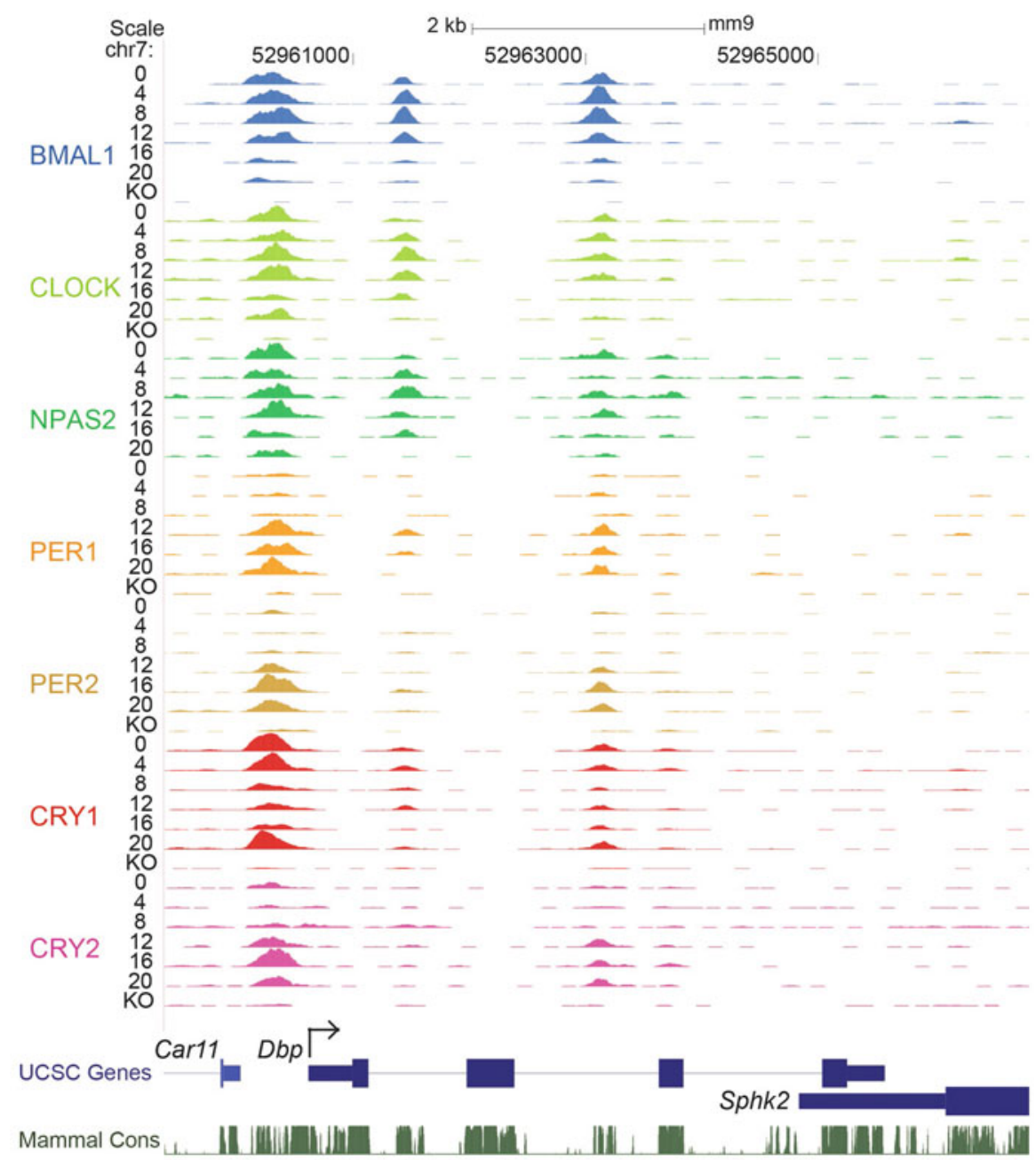

Fig. 4 UCSC genome browser view of ChIP-seq profiles of circadian transcription factors at the Dbp gene at six circadian times of day. BMAL1 (blue), CLOCK (green), NPAS2 (dark green), PER1 (orange), PER2 (gold), CRY1 (red), CRY2 (pink). 0, 4, 8, 12, 16, 20 CT (h). KO knockout. (From Koike et al. 2012)

BMAL1 and RNAPII-Ser5P binding sites, suggesting that CLOCK:BMAL1 could recruit and initiate RNAPII but CRY1 repressed the complex leading to a "poised" state.

Given the genome-wide circadian rhythms of RNAPII occupancy, we assessed chromatin states associated with transcription initiation and elongation during the circadian cycle. Figure 6 shows a browser view of six histone modifications that are characteristic of promoters, enhancers and transcription elongation (Kim et al. 2005; Barski et al. 2007; Guenther et al. 2007; Li et al. 2007; Creyghton 


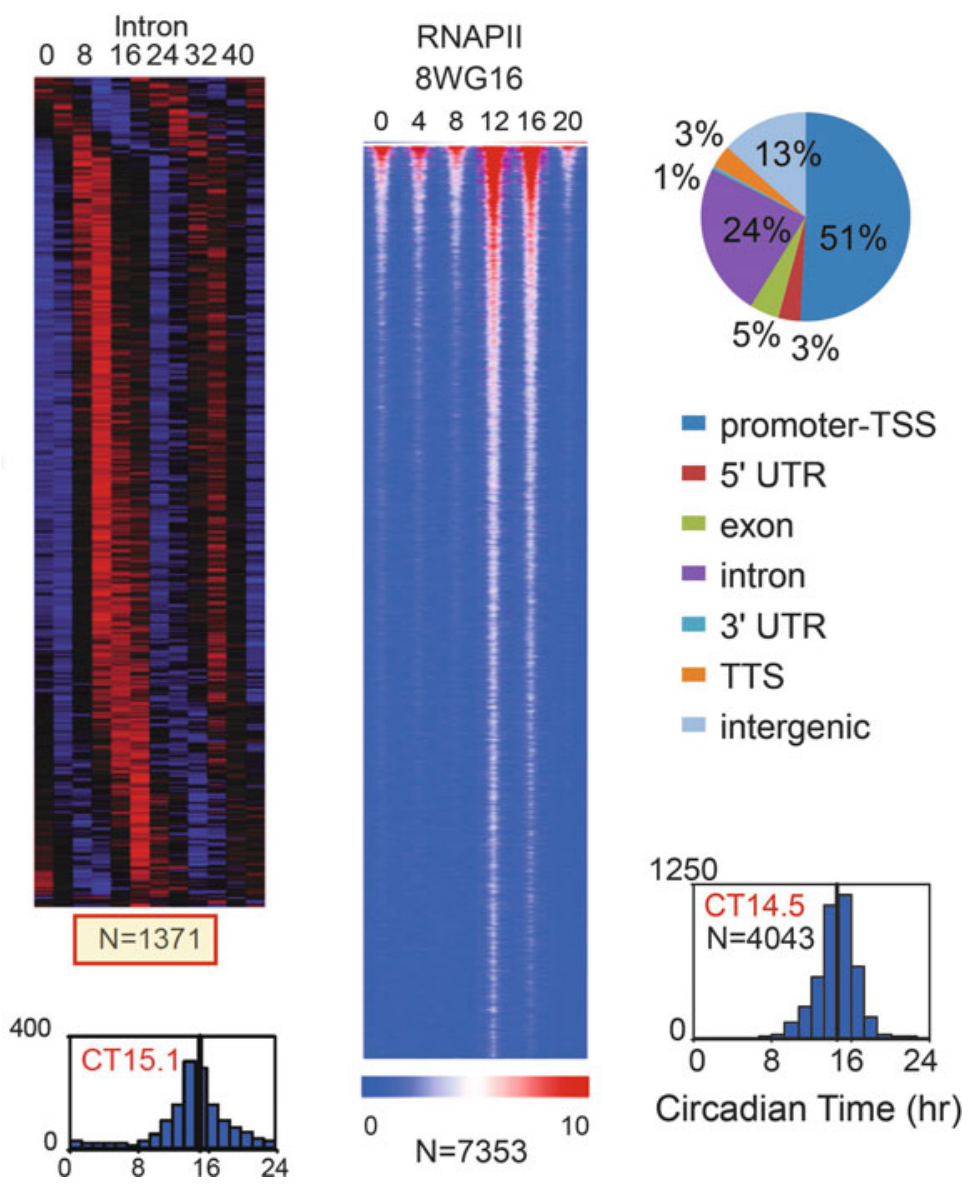

Fig. 5 Heatmap views of cycling intron RNA genes (left) and RNAPII-8WG16 occupancy (right). More than 4000 peaks had significant circadian RNAPII binding (From Koike et al. 2012)

et al. 2010; Ong and Corces 2011; Rada-Iglesias et al. 2011). Histone H3K4me3, $\mathrm{H} 3 \mathrm{~K} 9 \mathrm{ac}$ and $\mathrm{H} 3 \mathrm{~K} 27 \mathrm{ac}$ are enriched at promoters and show robust circadian rhythms in occupancy at the $D b p$ gene. When examined across the genome, we found that circadian rhythms in RNAPII occupancy as well as histone H3K4me3, $\mathrm{H} 3 \mathrm{~K} 9 \mathrm{ac}$ and $\mathrm{H} 3 \mathrm{~K} 27 \mathrm{ac}$ modifications occurred in the majority of expressed genes, even in cases where cycling RNA could not be detected. Thus a third surprise in this work was the observation that chromatin states were being modulated in a circadian manner across the genome in the liver.

What accounts for these genome-wide circadian rhythms in RNAPII occupancy and histone modifications? Examination of the relationship between circadian transcription factor occupancy and gene expression shows that approximately $90 \%$ of genes bound by these factors are expressed whereas only $1-5 \%$ of unexpressed genes are similarly bound (Koike et al. 2012). These results 


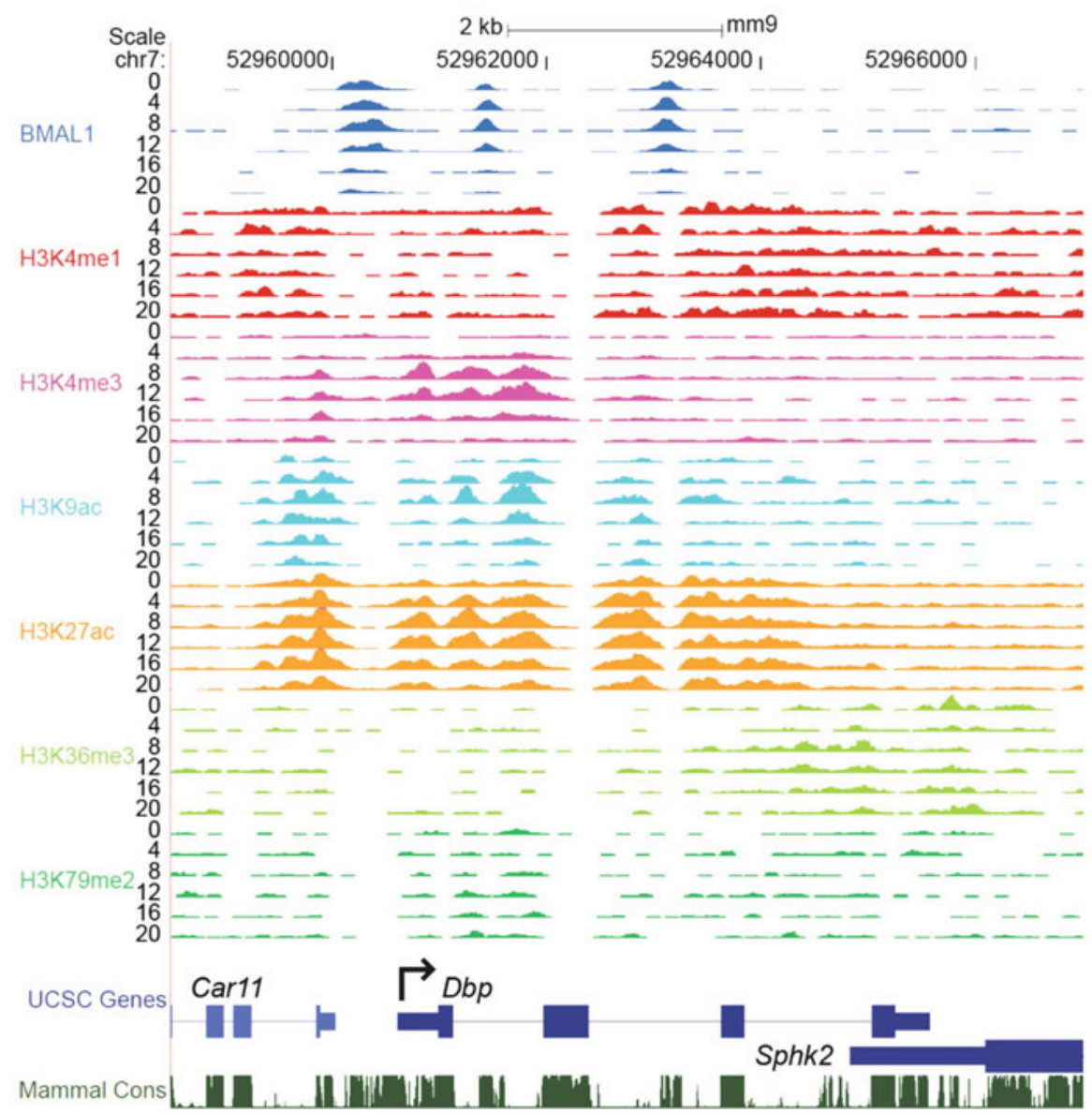

Fig. 6 UCSC genome browser view of histone methylation and acetylation at the $D b p$ gene. BMAL1 (blue), H3K4me1 (red), H3K4me3 (pink), H3K9ac (aqua), H3K27ac (orange), H3K36me3 (green), H3K79me2 (dark green) (From Koike et al. 2012)

demonstrate that gene expression per se rather than rhythmic gene expression is tightly correlated with circadian transcription factor binding. Rhythmic circadian transcription factor occupancy in turn could then be responsible for RNAPII recruitment and initiation on a genome-wide basis, which would then lead to the global rhythmic histone modifications seen here. Thus, circadian transcriptional regulators appear to be involved in the initial stages of RNAPII recruitment and initiation and the histone modifications associated with these events to set the stage for gene expression on a global scale, but additional control steps must then determine the ultimate transcriptional outputs from these sites.

In summary, we have defined the cis-regulatory network of the entire core circadian transcriptional regulatory loop on a genome scale and found a highly stereotyped, time-dependent pattern of core transcription factor binding, RNAPII 


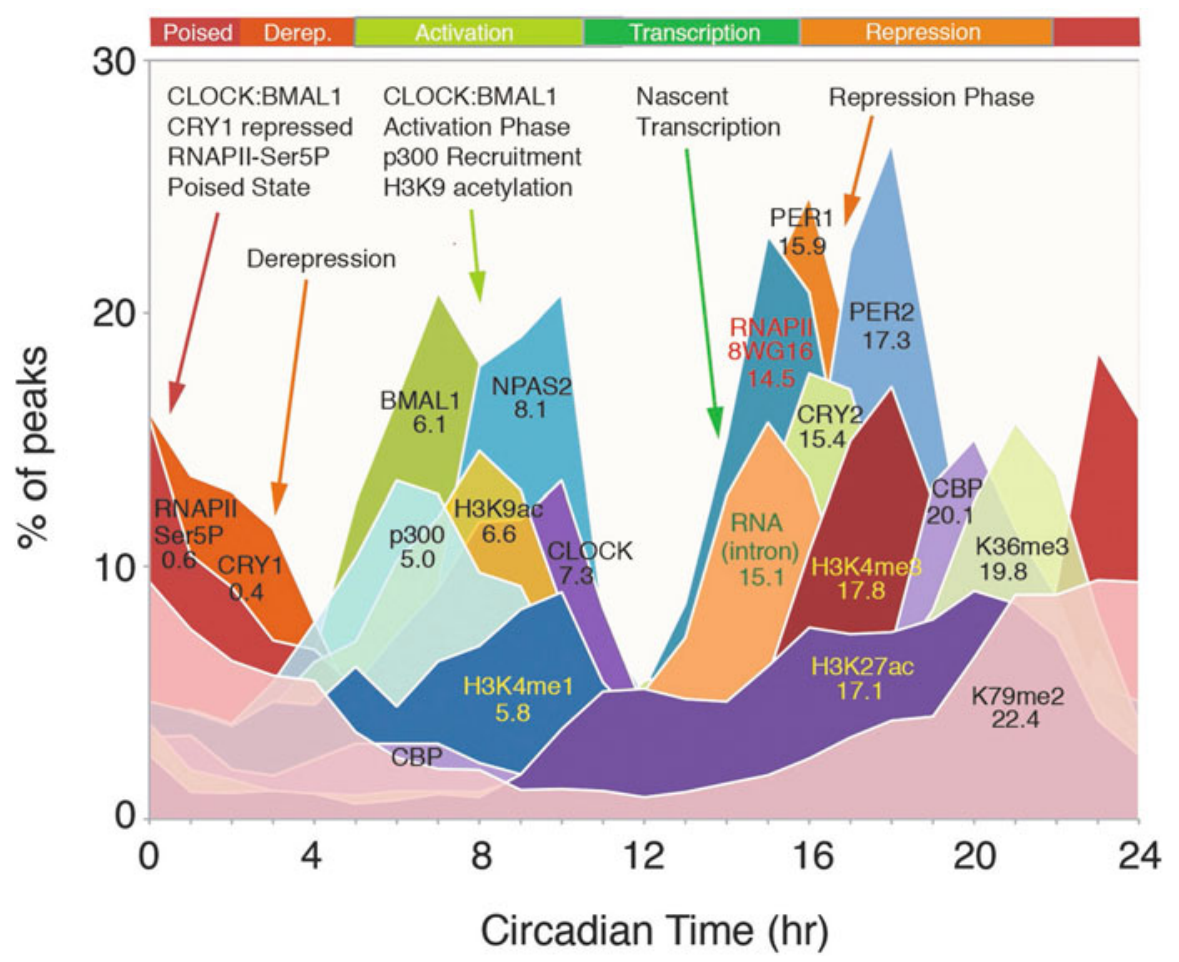

Fig. 7 Circadian transcriptional landscape in the liver. Histograms show the phase distributions of each factor as a function of time of day. Derep derepression (From Koike et al. 2012)

occupancy, RNA expression and chromatin states (Fig. 7). We defined three distinctive phases of the circadian cycle: (1) a poised phase in which CLOCK: BMAL1 and CRY1 bind to E-box sites in a transcriptionally silent state associated with RNAPII-Ser5P; (2) a temporally coordinated transcriptional activation phase in which RNAPII and p300 recruitment, pre-mRNA transcript expression, and H3K9ac, H3K4me3 and H3K27ac occupancy oscillate; and (3) a repression phase in which PER1, PER2 and CRY2 occupancy peaks. Circadian modulation of RNAPII recruitment and chromatin remodeling occurs on a genome-wide scale far greater than that seen previously by gene expression profiling. Thus, the circadian clock in the liver modulates the occupancy of RNAPII across the genome, leading at least in part to genome-wide circadian modulation of chromatin states that, in turn, poise the genome for transcription on a daily basis to act in concert with the daily metabolic demands of the organism.

Acknowledgment J.S.T. is an Investigator in the Howard Hughes Medical Institute. Research also supported by awards from the NIH. 
Open Access This chapter is distributed under the terms of the Creative Commons AttributionNoncommercial 2.5 License (http://creativecommons.org/licenses/by-nc/2.5/) which permits any noncommercial use, distribution, and reproduction in any medium, provided the original author(s) and source are credited.

The images or other third party material in this chapter are included in the work's Creative Commons license, unless indicated otherwise in the credit line; if such material is not included in the work's Creative Commons license and the respective action is not permitted by statutory regulation, users will need to obtain permission from the license holder to duplicate, adapt or reproduce the material.

\section{References}

Antoch MP, Song EJ, Chang AM, Vitaterna MH, Zhao Y, Wilsbacher LD, Sangoram AM, King DP, Pinto LH, Takahashi JS (1997) Functional identification of the mouse circadian Clock gene by transgenic BAC rescue. Cell 89:655-667

Barski A, Cuddapah S, Cui K, Roh TY, Schones DE, Wang Z, Wei G, Chepelev I, Zhao K (2007) High-resolution profiling of histone methylations in the human genome. Cell 129:823-837

Buhr ED, Yoo SH, Takahashi JS (2010) Temperature as a universal resetting cue for mammalian circadian oscillators. Science 330:379-385

Busino L, Bassermann F, Maiolica A, Lee C, Nolan PM, Godinho SI, Draetta GF, Pagano M (2007) $\mathrm{SCF}^{\mathrm{Fbxl} 3}$ controls the oscillation of the circadian clock by directing the degradation of cryptochrome proteins. Science 316:900-904

Chapman RD, Heidemann M, Albert TK, Mailhammer R, Flatley A, Meisterernst M, Kremmer E, Eick D (2007) Transcribing RNA polymerase II is phosphorylated at CTD residue serine-7. Science 318:1780-1782

Crane BR (2012) Biochemistry. Nature's intricate clockwork. Science 337:165-166

Creyghton MP, Cheng AW, Welstead GG, Kooistra T, Carey BW, Steine EJ, Hanna J, Lodato MA, Frampton GM, Sharp PA, Boyer LA, Young RA, Jaenisch R (2010) Histone H3K27ac separates active from poised enhancers and predicts developmental state. Proc Natl Acad Sci USA 107:21931-21936

Czarna A, Berndt A, Singh H, Grudziecki A, Ladurner A, Timinszky G, Kramer A, Wolf E (2013) Structures of Drosophila cryptochrome and mouse cryptochrome1 provide insight into circadian function. Cell 153:1394-1405

Fuda N, Ardehali M, Lis J (2009) Defining mechanisms that regulate RNA polymerase II transcription in vivo. Nature 461:186-192

Gallego M, Virshup DM (2007) Post-translational modifications regulate the ticking of the circadian clock. Nat Rev Mol Cell Biol 8:139-148

Gekakis N, Staknis D, Nguyen HB, Davis FC, Wilsbacher LD, King DP, Takahashi JS, Weitz CJ (1998) Role of the CLOCK protein in the mammalian circadian mechanism. Science 280:1564-1569

Guenther MG, Levine SS, Boyer LA, Jaenisch R, Young RA (2007) A chromatin landmark and transcription initiation at most promoters in human cells. Cell 130:77-88

Hennig S, Strauss H, Vanselow K, Yildiz O, Schulze S, Arens J, Kramer A, Wolf E (2009) Structural and functional analyses of PAS domain interactions of the clock proteins Drosophila PERIOD and mouse PERIOD2. PLoS Biol 7:e94

Hong HK, Chong JL, Song W, Song EJ, Jyawook AA, Schook AC, Ko CH, Takahashi JS (2007) Inducible and reversible Clock gene expression in brain using the tTA system for the study of circadian behavior. PLoS Genet 3:e33 
Huang N, Chelliah Y, Shan Y, Taylor CA, Yoo SH, Partch C, Green CB, Zhang H, Takahashi JS (2012) Crystal structure of the heterodimeric CLOCK:BMAL1 transcriptional activator complex. Science 337:189-194

Hughes ME, Hong HK, Chong JL, Indacochea AA, Lee SS, Han M, Takahashi JS, Hogenesch JB (2012) Brain-specific rescue of Clock reveals system-driven transcriptional rhythms in peripheral tissue. PLoS Genet 8:e1002835

Jones JC, Phatnani HP, Haystead TA, MacDonald JA, Alam SM, Greenleaf AL (2004) C-terminal repeat domain kinase I phosphorylates Ser2 and Ser5 of RNA polymerase II C-terminal domain repeats. J Biol Chem 279:24957-24964

Kim TH, Barrera LO, Zheng M, Qu C, Singer MA, Richmond TA, Wu Y, Green RD, Ren B (2005) A high-resolution map of active promoters in the human genome. Nature 436:876-880

King DP, Zhao Y, Sangoram AM, Wilsbacher LD, Tanaka M, Antoch MP, Steeves TD, Vitaterna MH, Kornhauser JM, Lowrey PL, Turek FW, Takahashi JS (1997) Positional cloning of the mouse circadian clock gene. Cell 89:641-653

Ko CH, Yamada YR, Welsh DK, Buhr ED, Liu AC, Zhang EE, Ralph MR, Kay SA, Forger DB, Takahashi JS (2010) Emergence of noise-induced oscillations in the central circadian pacemaker. PLoS Biol 8:e1000513

Koike N, Yoo SH, Huang HC, Kumar V, Lee C, Kim TK, Takahashi JS (2012) Transcriptional architecture and chromatin landscape of the core circadian clock in mammals. Science 338:349-354

Kornmann B, Schaad O, Bujard H, Takahashi JS, Schibler U (2007) System-driven and oscillatordependent circadian transcription in mice with a conditionally active liver clock. PLoS Biol 5: e34

Kucera N, Schmalen I, Hennig S, Öllinger R, Strauss H, Grudziecki A, Wieczorek C, Kramer A, Wolf E (2012) Unwinding the differences of the mammalian PERIOD clock proteins from crystal structure to cellular function. Proc Natl Acad Sci USA 109:3311-3316

Lamia K, Papp S, Yu R, Barish G, Uhlenhaut N, Jonker J, Downes M, Evans R (2011) Cryptochromes mediate rhythmic repression of the glucocorticoid receptor. Nature 480:552-556

Li B, Carey M, Workman JL (2007) The role of chromatin during transcription. Cell 128:707-719

Liu AC, Welsh DK, Ko CH, Tran HG, Zhang EE, Priest AA, Buhr ED, Singer O, Meeker K, Verma IM, Doyle FJ 3rd, Takahashi JS, Kay SA (2007) Intercellular coupling confers robustness against mutations in the SCN circadian clock network. Cell 129:605-616

Lowrey PL, Takahashi JS (2000) Genetics of the mammalian circadian system: photic entrainment, circadian pacemaker mechanisms, and posttranslational regulation. Annu Rev Genet 34:533-562

Lowrey PL, Takahashi JS (2004) Mammalian circadian biology: elucidating genome-wide levels of temporal organization. Annu Rev Genomics Hum Genet 5:407-441

Lowrey PL, Takahashi JS (2011) Genetics of circadian rhythms in mammalian model organisms. Adv Genet 74:175-230

Meng QJ, Logunova L, Maywood ES, Gallego M, Lebiecki J, Brown TM, Sladek M, Semikhodskii AS, Glossop NR, Piggins HD, Chesham JE, Bechtold DA, Yoo SH, Takahashi JS, Virshup DM, Boot-Handford RP, Hastings MH, Loudon AS (2008) Setting clock speed in mammals: the CK1 epsilon tau mutation in mice accelerates circadian pacemakers by selectively destabilizing PERIOD proteins. Neuron 58:78-88

Mohawk JA, Green CB, Takahashi JS (2012) Central and peripheral circadian clocks in mammals. Annu Rev Neurosci 35:445-462

Nagoshi E, Saini C, Bauer C, Laroche T, Naef F, Schibler U (2004) Circadian gene expression in individual fibroblasts; cell-autonomous and self-sustained oscillators pass time to daughter cells. Cell 119:693-705

Nangle SN, Rosensweig C, Koike N, Tei H, Takahashi JS, Green CB, Zheng N (2014) Molecular assembly of the period-cryptochrome circadian transcriptional repressor complex. Elife 3: $\mathrm{e} 03674$ 
Ong CT, Corces VG (2011) Enhancer function: new insights into the regulation of tissue-specific gene expression. Nat Rev Genet 12:283-293

Preitner N, Damiola F, Lopez-Molina L, Zakany J, Duboule D, Albrecht U, Schibler U (2002) The orphan nuclear receptor REV-ERB $\alpha$ controls circadian transcription within the positive limb of the mammalian circadian oscillator. Cell 110:251-260

Rada-Iglesias A, Bajpai R, Swigut T, Brugmann SA, Flynn RA, Wysocka J (2011) A unique chromatin signature uncovers early developmental enhancers in humans. Nature 470:279-283

Ripperger JA, Schibler U (2006) Rhythmic CLOCK-BMAL1 binding to multiple E-box motifs drives circadian Dbp transcription and chromatin transitions. Nat Genet 38:369-374

Siepka SM, Yoo SH, Park J, Song W, Kumar V, Hu Y, Lee C, Takahashi JS (2007) Circadian mutant overtime reveals F-box protein FBXL3 regulation of cryptochrome and period gene expression. Cell 129:1011-1023

Sims RJ 3rd, Belotserkovskaya R, Reinberg D (2004) Elongation by RNA polymerase II: the short and long of it. Genes Dev 18:2437-2468

Takahashi JS, Pinto LH, Vitaterna MH (1994) Forward and reverse genetic approaches to behavior in the mouse. Science 264:1724-1733

Vitaterna MH, King DP, Chang AM, Kornhauser JM, Lowrey PL, McDonald JD, Dove WF, Pinto LH, Turek FW, Takahashi JS (1994) Mutagenesis and mapping of a mouse gene, Clock, essential for circadian behavior. Science 264:719-725

Welsh DK, Yoo SH, Liu AC, Takahashi JS, Kay SA (2004) Bioluminescence imaging of individual fibroblasts reveals persistent, independently phased circadian rhythms of clock gene expression. Curr Biol 14:2289-2295

Welsh DK, Takahashi JS, Kay SA (2010) Suprachiasmatic nucleus: cell autonomy and network properties. Annu Rev Physiol 72:551-577

Xing W, Busino L, Hinds T, Marionni S, Saifee N, Bush M, Pagano M, Zheng N (2013) SCFFBXL3 ubiquitin ligase targets cryptochromes at their cofactor pocket. Nature 496:64-68

Yoo SH, Yamazaki S, Lowrey PL, Shimomura K, Ko CH, Buhr ED, Siepka SM, Hong HK, Oh WJ, Yoo OJ, Menaker M, Takahashi JS (2004) PERIOD2::LUCIFERASE real-time reporting of circadian dynamics reveals persistent circadian oscillations in mouse peripheral tissues. Proc Natl Acad Sci USA 101:5339-5346

Yoo SH, Mohawk JA, Siepka SM, Shan Y, Huh SK, Hong HK, Kornblum I, Kumar V, Koike N, Xu M, Nussbaum J, Liu X, Chen Z, Chen ZJ, Green CB, Takahashi JS (2013) Competing E3 ubiquitin ligases govern circadian periodicity by degradation of CRY in nucleus and cytoplasm. Cell 152:1091-1105 